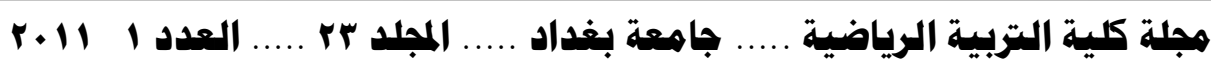

اثر بزناهمج تدرببدي هقتزح لتنشميهة التمهمل الهوائي في

كزة السلة على سوعة اداء همهارة الملماورة لدى طالبات

الروحلة الثانية في كلية التزبية الرياضية

م. جــاد رزوقةي وهيسـبـ

كلية التزبية الرباضية - جامهمة بغداد

Pr.

$\Delta \mid \leq \mathbb{|}$

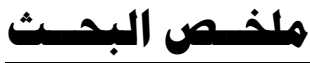

تعتبر كرة السلة نشاطا رياضيا يعتمد على المهارات الاساسية كقاعدة هامة للتقدم سواء كان على مستوى اللاعب او الفريق.

ان نجاح الفريق يتوقف على التريب المستمر وإتقان اللاعب المهارات الاساسية وهذا يتطلب التدريب لساعات طويلة في مناخ يحيطه الاخلاص والرغبة الحقيقية. لقد استخدم الباحث المنهج التجريبي على عينة عددهم (ro) طالبة من المرحلة الثانية وتم تقسيمهم الى مجموعتين ، المجموعة الضابطة والمجموعة التجريبية وعدد كل مجموعة ( • 1) طالبات وإختيار (r) طالبات للتجربة الاستطلاعية وإستبعاد طالبتين بسبب الاصابة وعدم استطاعتهن تكملة الاختبار. وق استتتج الباحث ان البرنامج المطبق على المجموعة التجريبية له تأثير ايجابي على افراد العينة، كما ظهر بعض الفروقات بين الاوساط الحسابية ولصالح المجموعة التجريبية وقد اوصى الباحث بضرورة ادخال التمارين التلاهوائية ضمن برنامج الوحدات التدريبية وخاصة لاى افراد فرق الدرجة الاولى والممتاز. 


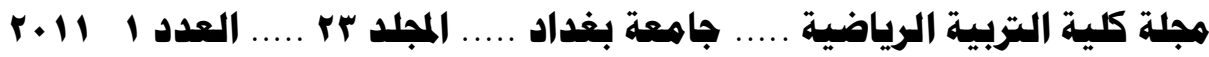

Effect of proposed training program in developing anaerobic endurance on basketball skills performance for sophomore girls in Baghdad University

Basketball considered sport activities which depend upon basic skills for achievement. The aim of this study was to propose a anaerobic training program for sophomore girls in college of physical education. The study hypothesized that this program will enhance skill achievement in basketball. Sample was (25) sophomore female students. Thy divided in tow group, experimental and control, both groups underwent basketball test to the training program.

Experimental group look 12 anaerobic training drills (once week) while the control group took the traditional training program for the same period. After training sessions, both groups were retested with the same test under the same manners.

Results showed differences between the two groups in most skills tests which indicate the superiority of the experimental group. The results confirm the necessity of anaerobic training in skill learning.

\section{البـاب الأول}

| - التعريف بالبحث

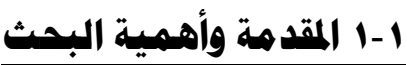

تعتبر كرة السلة نشاطا رياضيا يعتمد على المهارات الاساسية كقاعدة هامة للتقدم سواء كان على مستوى اللاعب او الفريق. وان نجاح الفريق يتوقف على التدريب المستمر واتقان اللاعبين للمهارات الاساسية وهذا يتطلب التريب لساعات طويلة في مناخ يحيطه الاخلاص والرغبة الحقيقية.

لان المهارات الاساسية والقدرة على ادائها وسرعة اتقانها شيء هام وعامل جوهري لنجاح الفريق لللك فالقدرة على اتقانها يتوقف بشكل مباشر على التدريب المنتظم مع التركيز على كافة المهارات الاساسية الدفاعية واللهجومية التي يجب ان يتعلمها $(\bullet \cdot)$ 


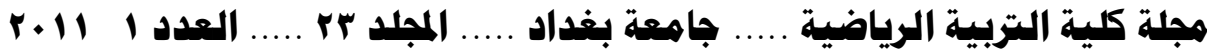

اللاعب بصفة عامة مثل مسك الكرة وإتتلامها والتمريز بانواعه والتصويب والمحاورة. حيث تعتبر المحاورة من اصعب المهارات الفنية اداء في كرة السلة وهي تدل على مدى التوافق العضلي العصبي للعينين ويقية اعضاء الجسم وهي كمهارة فردية ضرورية في كرة

(السلة. (1)

حيث يتوقف بالمحاورة بالكرة على قدرة اللاعب على ملاحظة ما يجري في الملعب وتقدير المسافات بين زملائه ومنافسيه فيجب ان تكون لايه القدرة على المحاورة دون النظر الى الكرة.

وان لعبة كرة السلة تتطلب بلد اندفاعات متفجرة من الطاقة لفترة زمنية قصيرة، حيث يلعب اللاعب اريعون دقيقة ملعوية دون ان يؤثر التعب على مستوى ادائه، لعبة كرة السلة تتطلب بناء قاعدة هوائية جيدة وتعمل على اعداد الجهازين الدوري والتنفسي للعمل الاكثر شدة. وتعمل على تنمية التحمل ونظام الطاقة للالياف العضلية بطيئة الانقباض

ويعد تكوين الاساس الهوائي.

ويتم التدريب على القدرة اللاهوائية اي التدريب على العمل اللاهوائي وفيها يكون التركيز على تكوين المقدرة الهوائية في الالياف الكليكوجينية سريعة التاكسد، ويعد ذلك يتم تنمية النظام اللاهوائي الأي يؤدي الى تطوير مصادر وممرات قصيرة المدى ،فعندما يزيد نبض اللعب اثناء التمرين يشير الى انتقال تدريجي من ممرات الطاقة الهوائية الى ممرات الطاقة الكلاهوائية.

فالحمل ذو الثدة العالية (الحالة اللاهوائية) والحمل الاقل من الاقصى (الحالة الهوائية) ذا الهمية كبيرة للمقدرة الوضيفية للفرد، لرفع مستوى الطاقة الهوائية وإللاهوائية. 


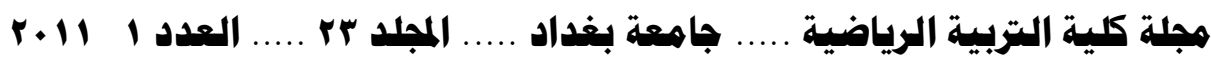

وان اللياقة البدنية الوظيفية تعتمد كليا على مصادر الطاقة الهوائية والطاقة

(1) الناهوائية.

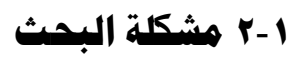

ان اكثر البحوث تدل على ان اكثر التلاعبين لايستطيعون انهاء المباريـات بنفس

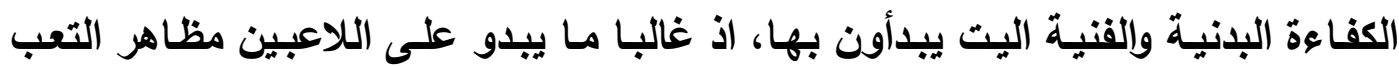
والاجهاد بصـورة واضحة ممـا يدل على قصور في الكفاعة البلنيـة والقنيـة في لعبـة كرة السلة حيث يتطلب بذل اندفاعات متفجرة في الطاقة (ץ) في ازمنة قصيرة نسبيا.

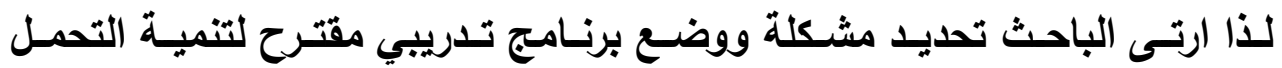
اللاهوائي واثثره على دقة اداء مهارة المحاورة لدى طالبات المرحلة الثانية واجراء اختبارات قبليـة على عينـة البحث لتحديد بعض المتغيرات الضـرورية مسن جراء تطبيق البرنـامج المقترح واجـراء اختبـارات بعديـة لمعرفـة مـدى تـأثير هذا البرنـامج على تنميـة التحمـل اللاهوائي وائره على سرعة اداء مهارة المحاورة.

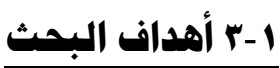

يهدف الباحث من خلال هذا البحث للتعرف على ما يلي: ا ـ اعداد برنامسج تدريبي مقترح لتتمية التحمل التلاهوائي على دقة اداء مهارة المحاورة بكرة السلة. r. معرفة التقدم الحاصل على اداء مهارة المحاورة للدى طالبـات المرحلـة الثانية في الاختبارين القبلي والبعدي.

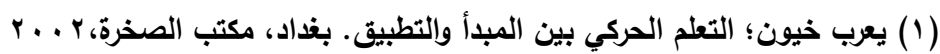

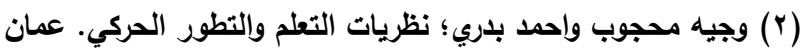




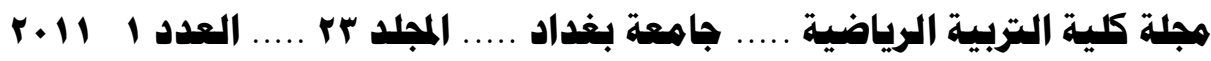

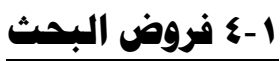

1. هناك فروق ذات دلالة احصائية بين الاختبارين القبلي البعدي لصـالح القياسـات

$$
\text { البعدية في التحمل التلاهوائي قيد البحث. }
$$

r. هناك فروق ذات دلالة احصائية بين الاختبارين القبلي والبعدي في دقة المحاورة

ولصالح الاختبار البعدي.

ا 0 - مهالات البحث

1-0-1 المجال البشري: مجموعة من طالبات المرحلة الثانية في كلية التربية الرياضية

$$
\text { والبالغ عددهم (ro) طالبة . }
$$

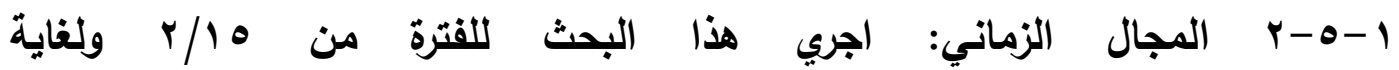

$$
. r \cdot 1 \cdot / \varepsilon / 17
$$

1-0-0 المجال المكاني: القاعة الداخلية في كلية التربية الرياضية

\section{البــاب الثانـي}

r - r الدراسات النظرية والدارسات المشابهة

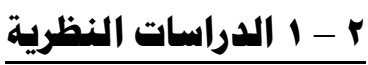

r- r-r - العمل الهوائي

يطلق احيانا على العمل الهوائي نظام التحمل ويستخدم العمل الهوائي اثناء الاداء

الطويل باستخدام تمرينات ذات شدة منخفضة.

وكمـا نعلـم ان الطعـام هـو مصـدر الوقود الرئيسـي الـذي يتحـول الـى طاقـة، ان

التغيـرات الكيميائيـة التي تحدث في العضـلات العامـة والـتخلص مسن النـواتج الكيميائيـة

المختلفة.

حيث ان العضلات تحتاج الى كمية كبيرة من الطاقة اثناء اتقباضهها مستمدها من

المصدر الطاقة الاوكسجين هو : 


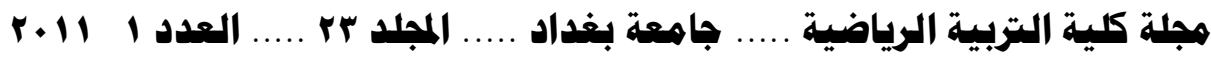

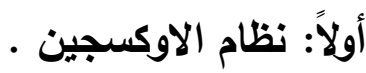

يتميزز هـا النظـام بوجـود الاوكسـجين لاعـادة بنـاء ثلاثـي ادينـوزني الفوسـفات بواسـة التكسير الكامل لجزيء كلايكوجين، والذي يصبح ثاني اوكسيد الكاريون وماء، وينتج عن

طاقة قدرها ^^ץ جزيئة فوسفات (').

وهنـاك مصدر اخر للطاقة هو غذائي عن طريـق اكسدة الدهون وتحويلها الحى

احماض دهنية ولكن اكسدة الدهون تحتاج كمية اوكسجين اكبر.

ثانياً: اثر التدريب على النظام الههوائي، لاعب كرة السلة،والأي يمتلك جهاز دوري تنفسي عالي الكفاءة، لا يشعر بالتعب الا في نهاية المباريات كما ان التدريب على النظام الهوائي

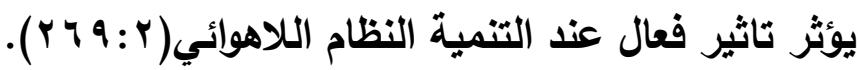
r- r- r العمل العلاهوائي

ان العمل اللاهوائي عبارة عن التغيرات الكيميائية التي تحدث فب العضلات العادية لانتاج الطاقة اللازمة لاداء المجهود مع عدم استخدام الاوكسجين الهوائي(؟) ، وتحتاج العضلات الى كمية كبيرة من الطاقة اثناء انقباضها نستمدها من مصدرين للطاقة هما:

\section{r r-l r- القدرة اللاهوائية القصوى}

هي قدرة الجسم على العمل مع كفاية الاوكسجين، ويمكن تقديرها من خلال اداء واجبات يستغر زمن ادائها (ه: . 1) ثواني وذلك مثل الجري لمسافات قصيرة والوثبات وغيرها.

ويمكن تنمية القدرة اللاهوائية القصوى وذلك باستخدام تدريبات العدو ذات الشدة المرتفعة التي تتراوح ما بين ( • -ه 9 \%) من اقصى سرعة للفرد الرياضي، كما يؤكد

(1) ابو العلا احمد؛ بيولوجيا الرياضية. القاهرة دار الفكر العبي، 1990

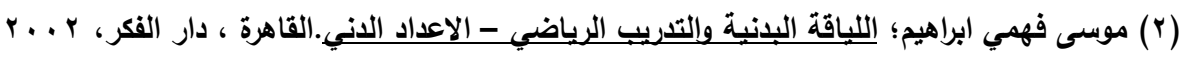


هبلة كلية التربية الرياضية .... جاهعة بغداد .... المبلد r. .... العدد ا

على انه هناك علاقة مباشرة بين الكفاءة اللاهوائية والقوة القصوى،حيث تزيل الكفاعة

اللاهوائية لاى الشخص الاقوى (').

r -1 - القدرة اللاهوائية والهوائية

تمثل علاقة كل ممن القدرة الهوائية والقدرة اللاهوائية بالتحمـل الدوري التنفسي

احدى المشكلات الاساسية في المجال الرياضي.

هنـاك عوامل كثيرة تتجكم في تحديد كفـاعة الجهاز الدوري التنفسي الهـها شدة

التدريب وفترة دوام النشاط وكمية العمل العالي الذي يحتويه هذا النشاط.

كمـا ان هنـاك العديد مـن الانشطة التي تعتمـ على المزج بين القدرات الهوائيـة

واللاهوائية مثل الجري( . . ع - . . ^) متر او السباحة ( . . ץ) متر، حيث انها تعتمد على كفـاءة توصسيل الاوكسـجين للعضـلات العاملـة بالاطافـة السى انتـاج الطاقـة اللاهوائيـة في

مجموعات عضلية كبيرة(r).

r r - - الباقة البدنية العاهمة

هي العمود الفقري والقاعدة العريضـة والداعمـة الاساسية للممارسـة الرياضية في

جميع مراحلها ولجميع المراحل السنية ، كما انها المطلب الرئيسي واللهدف المباشر الذي يسعى اليه الانسان من خلال ممارسته للانشطة الرياضية. واللياقة البدنيـة العامسة لاتختلف مس نشـاط الى اخر، فهي دعامـة كل الانشـة الحركية وحيث تتميز بثلاثة شروط اساسية هي:

ا ـ الشمول: وتعني التنمية الشاملة لجميع القدرات البدنية مثل القوة والسرعة والمرونـة

و الجلد..... الخ.

r. الاتزان: يعني ان تكون التنمية متوازية بحيث لا يميز مكون عن الاخر.

(1) ابو العلا احمد؛ بيولوجيا الرياضبة. القاهرة ،دار الفكر العربي، 99 19. (r) ابو العلا احمد؛ نفس المصدر السابق.

(00) 


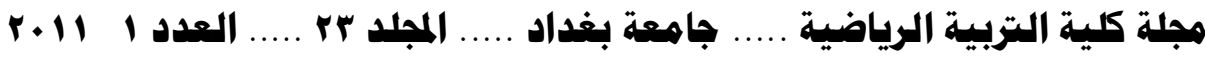

r. الحجم المناسب: يعني مناسبة التدرج في تطور اللياقة البذنية وفقا لامكانات الفرد البانيـة والموروثـة والمكتسبة دون ان يحقق هذا التدرج المستوى المناسب في

اللياقة البدنية وفقا لمتطلبات حياته(').

r r - الاياقة البدنية الخاصة

اللياقة البدنية الخاصـة متطلب اساسي ايضـا لكل نثـاط رياضي، ولكنها تختف من نشـاط الى اخر وذلك وفقا لطبيعة هذا النشاط ومتطلباته يلزم توافرها في ممارسي هذا النشـاط حتى يمنهم التقدم في التذريب والوصول الى المستويات العالية والتدريب لاكتساب اللياقة البدنية الخاصة يجب ان تتضمن على الاقّل ثلاثة اتجاهات اساسية هي: > ان يتضمن التدريبات المستخدمة نفس الاتجاه الحركي. \& ان تستخدم التدريبات نفس الاجهزة العضوية المستخدمة في نوع النشاط المعين. \& يفضل استخدام نفس الادوات المستعملة في نشاط معين

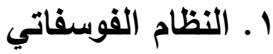

يعتبر ثلاثي ادينوزني الفوسفات المصدر المباشر لانتاج الطاقة فنجد ان انشطار المواد الغذائية يستخدم في تكوين هذا المركب ويخزن في جميع اجزاء الجسم وتعتمد خلايـا الجسم على الطاقة الناتجـة من انشطار ثلاثي ادينوزني الفوسفات.

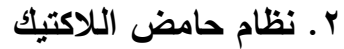

ان مخزون الطاقة من ثلاثي ادينوزيني الفوسفات الكرياتين يستهلك سريعا غي خلال ( • 1) ثواني تقريبا لألك يجب ان يكون هناك مصدرا للطاقة لكي تستطيع العضلات

الاستقرار في الاداء (r)

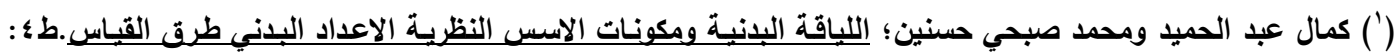

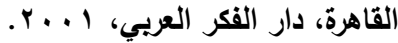

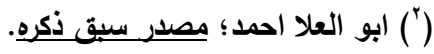




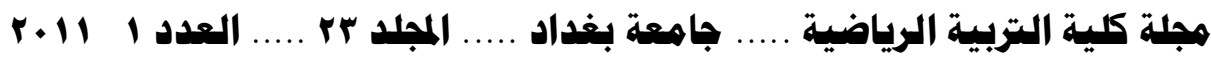

وهذا المصدر يكون مصدرا غذائيا ناتج عن عملية التمثيل الغذائي للكاريوهيدرات التي تتحول الى صورة بسيطةفي شكل سكر كلوكوز . والذي يستخدم في انتاج الطاقة او يخزن في الكبد في صورة كليكوجين. اثر التدريب على العمل اللاهوائي يؤدي السى زيـادة كفاءة الفرد في اداء الانشطة التئي

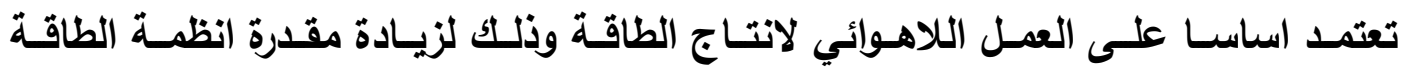

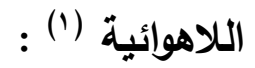

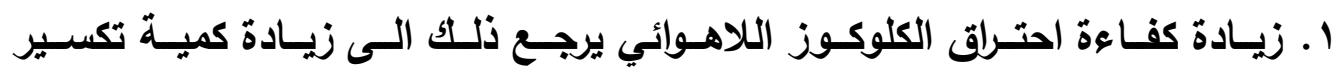
الكلايكوجين الى حامض اللاكتك. r · زيادة مقدرة ثلاثي ادينوزني الفوسفات الكرياتين لانتاج الطاقة وذلكك نتيجة لزيادة مستوى المخزون العضلي وزيادة نثاط انزيم الكرياتين.

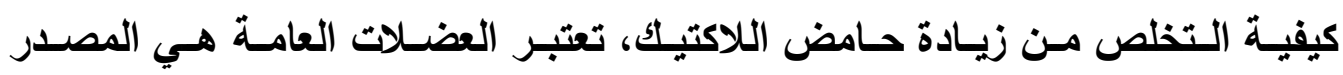

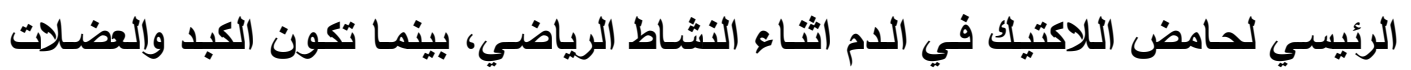

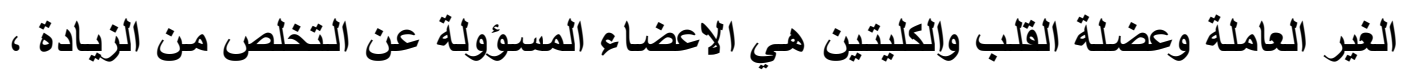
الا ان الكبد هو المسؤول الاول عن تحويل حامض اللاكتيك الى كلايكوجين عن طريق

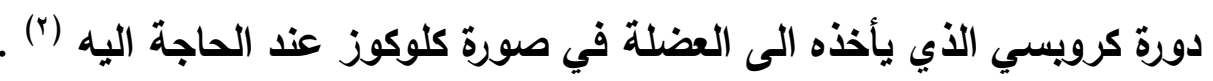

(1) (ابو العلا احمد ومحمد حسن علاوي؛ فسيولوجيا التدريب الرياضي.طا القاهر ، دار الفكر العربي. (r) ابو العلا احمد ومحمد حسن علاوي إنفس المصدر السابق. 


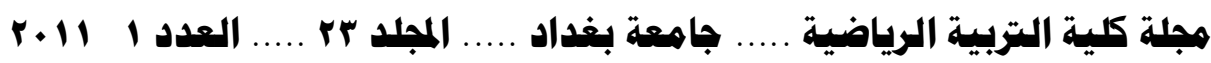

\section{البـاب الثالـث}

r- بنهج البحث واجزاءاته الميدانية

r-r بنهج البحث البيثر

استخدم الباحث المنهج التجريبي لملائمته لطبيعة البحث حيث تم اجراء اختبارات

قبلية ويعدية ووضع برنامج تلديبي مقترح لتنمية التحمل اللاهوائي على دقة اداء مهارة

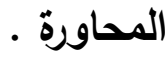

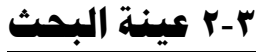

تم اختيار عينة البحث بالطريقة العمدية من طالبات المرحلة الثانية والبالغ عددهم (Y0) طالبة حيث تم تقسيمهم الى مجموعة ضابطة وعددها ( • (1) ومجموعة تجريبية

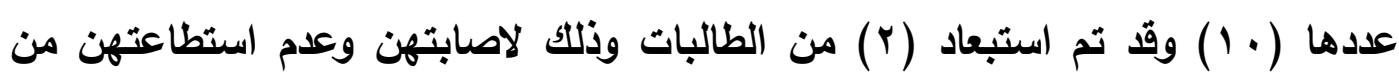

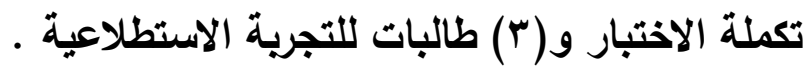

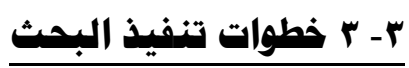

لقد قام الباحث بتصـيم استمارة لجمـع المعلومـات الخاصـة بالاختبـارات القبليـة والبعدية تتضمن مجموعة من الاختبارات ذات العلاقة بموضوع البحث وتم عرض الاستماتمارة

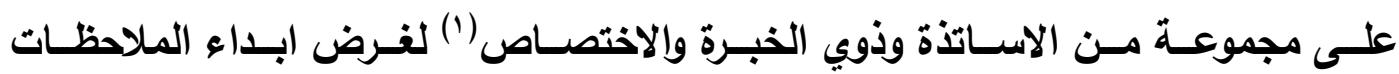

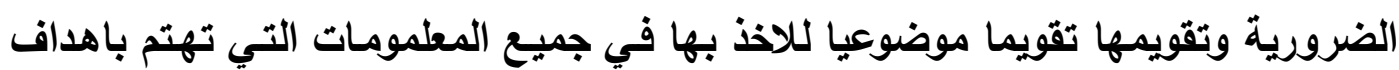

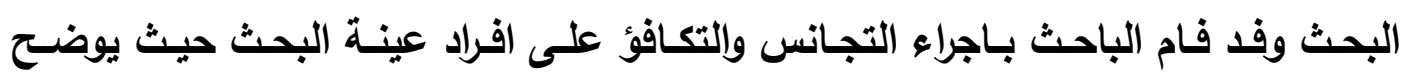
الجدول (1) الوسط الحسابي والانحراف المعياري والوسيط وقيمة معامل الالتواء على عينة

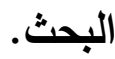

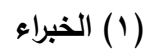

- أ - أد مازن عبد الرحمن / استاذ مادة كرة السلة. - أ. أد سلمان نصيف / استاد مادة كرة السلة. - أ. - أد اسعد عبد الغزيز / استاذ مادة كرة السلة. $(\bullet \wedge)$ 


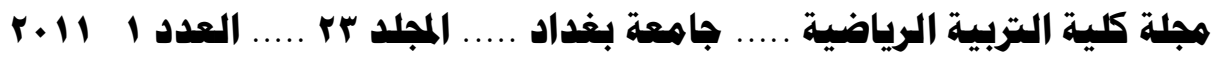

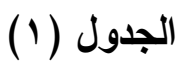

يبين الوسط الحسابي والانحراف المعياري والوسيط وقيمة معامل الالتواء

\begin{tabular}{|c|c|c|c|c|c|}
\hline معامل الالتواء & الوسيط & $-\varepsilon$ & س - & وحدة القياس & المتغيرات \\
\hline$\cdot, \wedge r$ & $r, 10$ & $\cdot, 9 r$ & Y I, ^o & سنة & العمر \\
\hline$\cdot, 94$ & 1 & $\varepsilon, \wedge$ & $-17 \varepsilon, r$ & سم & الطول \\
\hline צ T, , & 90 & $r, Y I$ & 70,00 & كغم & الوزن \\
\hline
\end{tabular}

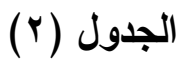

يبين الوسط الحسابي والانحراف المعياري وقيمة (ت) ستودينت لدلالة الفروق لمتوسطين غير مرتبطين وعينتين متساويتين

\begin{tabular}{|c|c|c|c|c|c|c|c|c|}
\hline \multirow{2}{*}{ دلالة } & \multirow{2}{*}{ الجيمة } & \multirow{2}{*}{ القيمة القيمة } & \multicolumn{2}{|c|}{ المجموعة الضابطة } & \multicolumn{2}{|c|}{ المجموعة التجريبية } & \multirow{2}{*}{ وحدة } & \multirow{2}{*}{ المتغيرات } \\
\hline & & & $-\varepsilon$ & س - & $-\varepsilon$ & س - & & \\
\hline \multirow{3}{*}{ غير دالة } & \multirow{3}{*}{$r, q r$} & \multirow{3}{*}{$r, .91$} & $\cdot, 91$ & $r r,+1$ & $\cdot, \vee \wedge$ & rl,rr & سنة & العمر العر \\
\hline & & & $r, \Lambda$ & $17 \leq, r$ & r,^I & 170,0 & 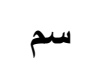 & الطول \\
\hline & & & $r, .1$ & $7 \leqslant, 0$ & $r, 1 r$ & 90,0 & كغم & 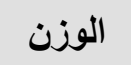 \\
\hline
\end{tabular}

\section{r - ع الاختبارات المستخدهة في البمث}

1 ـ اختبار قياس النبض قبل الجهد (وقت الراحة) وقياس النبض بعد الجهد مباشرة ،

قياس النبضات القلبية يتم احتساب النبض باصبع السبابة الوسطى بوضعهما على الشريان الايسر لمدة ( • 1) ثانية ثم يضرب *(؟) للحصول على الضربات القلبية في الدقيقة واحدة. 


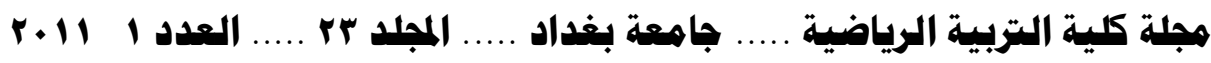

r. اختبار الوثب العمودي من الثبات / قياس القوة الانفجارية للرجلين. r. اختبار الجري المكوكي (الرشاقة) قياس الرشاقة مسافة (9) امتار ذهابا وايابا. ع. اختبار الجري لمسافة ( • ب) متر / قياس السرعة. هـ الوثب الطويل من الثبات / القوة الانفجارية للرجلين ('). r-ه التجربة الاستطلاعية

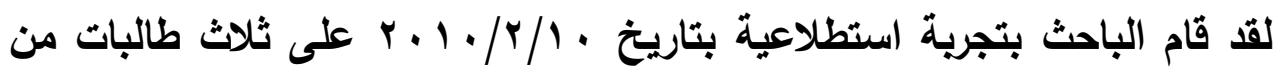
خارج مجتمع البحث وذلك للوقوف على المشاكل والعقبات التي تواجه عملية الاختبار. التجرية الرئيسية للاختبار القبلي للعينة الضابطة والعينة التجريبية

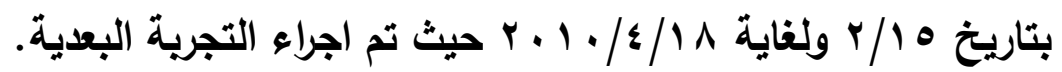
r- 1 ادوات البمث ا ـ أريط قياس.

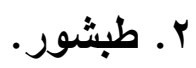

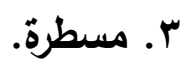

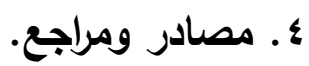

هـ ساعة توقيث.

צ. كرات سلة قانونية.

V. ملعب نظامي. ^. ميزان طبي لقياس الوزن. 


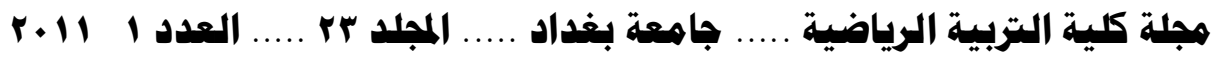

(1) r الوسائل الاحصائيسة

1. - الوسط الحسابي.

r ب الانحراف المعياري.

ب. (لوسيط.

ع. - معامل الالتواء.

هـ قيمة T المحتسبة (ستودنت).

\section{البـــاب الرابــع}

ع- عرض النتائج وهناقشتها

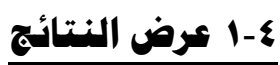

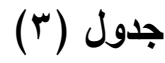

يبين الوسط الحسابي والانحراف المعياري وقيمة (ت) المحتسبة للمجموعة الضابطة والمجموعة التجريبية في الاختبارات القبلية

\begin{tabular}{|c|c|c|c|c|c|c|c|}
\hline \multirow[t]{2}{*}{ دلالة معنوية } & \multirow{2}{*}{ الجدولية } & \multirow{2}{*}{ المحتسبة } & \multicolumn{2}{|c|}{ الضجموعة } & \multicolumn{2}{|c|}{ التجريبية } & \multirow[t]{2}{*}{ المتغيرات } \\
\hline & & & $-\varepsilon$ & س- & $-\varepsilon$ & س- & \\
\hline غير معنوي & \multirow{6}{*}{$r, Y r$} & r & $r 1,1 \wedge$ & $11 \mathrm{~V}$ & $\varepsilon 0,7 r$ & 111 & التبض وقت الراحة \\
\hline غير معنوي & & $\cdot, \cdot V$ & $10, \cdot r$ & $\wedge, 7$ & $\Lambda, r r$ & $\wedge, q$ & سرعة . ب م \\
\hline غير معنوي & & $1, \wedge r$ & $r, \wedge r$ & r, ro & $r, 11$ & $r, 1$. & الوثب الى الاعلى \\
\hline غير معنوي & & $\cdot, \leqslant 9$ & $\{, 01$ & $1, r \mu$ & $\varepsilon, r V$ & $\cdot 9 \wedge$ & الوثب الطويل الثبات \\
\hline غير معنوي & & $r, 10$ & $10,0 \leq$ & $9, r$ & $1 \wedge, 1 \leq$ & 9,7 & الرشاقة \\
\hline غير معنوي & & $1, \leqslant r$ & r7,19 & 119 & $r 1, \leqslant \varepsilon$ & $1 \% 0$ & النبض بعد الجهـ \\
\hline
\end{tabular}

( ) وديع ياسين وحسن العبيدي ؛التطبيقات الاحصائية واستخدامات الحاسوب في التربية الرياضة. دار الكتب للطباعة والنشر ،

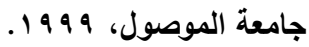


هجلة كلية التربية الرياضية .... جاهعة بغداد .... المبلد rr..... العدد ا

يبـين الجـدول(ب) الوسـط الحسـابي والانحـراف المعيـاري وقيمـة (ت) سـتودنت المحتسبة حيث ظهر وجود فروق ذات دلالة غير معنوية عند مستوى ـ 1, • في الاختبار القبلـي للمجموعـة التجريبيـة لان قيمـة (ت) المحتسـبة اصسفر مسن قيمسة (ت) الجدوليـة والبالغة ( r, Y ) في كافة متغيرات البحث مما يـل على ان البرنـامج المطبق لـ يكن لـه تاثير ايجابيا على افراد العينة رغم ظهور بعض الفروقات بي المتوسطات الحسـابية لصالح المجموعة التجريبية.

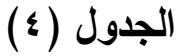

يبين الوسط الحسابي والانحراف المعياري وقيمة (ت) المحتسبة للمجموعة الضابطة والمجموعة التجريبية في الاختبارات البعدية

\begin{tabular}{|c|c|c|c|c|c|c|c|}
\hline \multirow{2}{*}{ دلالة معنوية } & \multirow{2}{*}{ الجدولية } & \multirow{2}{*}{ المحتسد } & \multicolumn{2}{|c|}{ المجموعة الضابطة } & \multicolumn{2}{|c|}{ التجمويبية } & \multirow{2}{*}{ المتغيرات } \\
\hline & & & $-\varepsilon$ & س- س & $-\varepsilon$ & س- & \\
\hline معنوي & \multirow{6}{*}{$r, r r$} & $1 \leqslant,{ }^{\prime}$ & $1 \Lambda, \leqslant V$ & $1 \ldots$ & $r q, 1 V$ & 111 & النبض وقت الراحة \\
\hline معنوي & & $r, Y \leqslant$ & $1 r, r q$ & V,Ir & $\Lambda, r$ & $\wedge, \vee$ & سرعة . ب م \\
\hline معنوي & & $r, v i$ & $\varepsilon, 1 r$ & $r, \& 1$ & $0, \cdot \varepsilon$ & $r, 10$ & الوثب الى الاعلى \\
\hline معنوي & & $\varepsilon, \cdot 0$ & $r, \wedge \varepsilon$ & $1, r 1$ & $\varepsilon, r$ & 1,11 & الوثب الطويل الثبات \\
\hline معنوي & & $r, Y T$ & $1 \leqslant, 0$ & $V, Y r$ & $\mid r, Y \Lambda$ & 9,7 & الرشاقة \\
\hline معنوي & & 7,0 & 7,0 & $11 \cdot, \mathrm{V}$ & $r q, 7 r$ & $1 r$ & النبض بعد الجهر \\
\hline
\end{tabular}

يبين الجدول (ع) الوسط الحسابي والانحراف المعياري وقيمة (ت) ستودنت المحتسبة حيث ظهر وجود فروق ذات دلالات معنوية عند مستوى ه., • في الاختبار البعدي للمجموعة الضابطة والمجموعة التجريبية. لان قيمة (ت) المحتسبة اكبر من قيمة (ت) الجدولية والبالغة (Y,Y ( ) في كافة متغيرات البحث ولصالح الاختبار البعدي وهذا يؤكد على ان البرنامج المعد للمجموعة التجريبية له ناثير ايجابي على كافة المتغيرات البدنية وعملية قياس النبض وقت الراحة ويعد الجهد المباشر. 


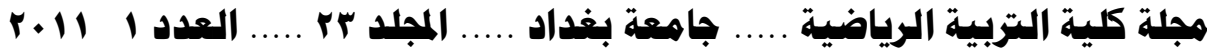

جدول (•)

يبين الوسط الحسابي والانحراف المعياري وقيمة (ت) المحتسبة للمجموعة التجريبية في الاختبارين القبلي والبعدي

\begin{tabular}{|c|c|c|c|c|c|c|c|}
\hline \multirow[t]{2}{*}{ دلالة معنوية } & \multirow{2}{*}{ الجدولية } & \multirow{2}{*}{ المحتّد } & \multicolumn{2}{|c|}{ المجموعة الضابطة } & \multicolumn{2}{|c|}{ التجريبية } & \multirow[t]{2}{*}{ المتغيرات } \\
\hline & & & $-\varepsilon$ & س- & ع & س- & \\
\hline معنوي & \multirow{6}{*}{$r, r r$} & $1 \leqslant, r_{0}$ & $1 \wedge, \leqslant V$ & $1 \ldots$ & $r 1,1 \wedge$ & $11 \mathrm{~V}$ & النبض وقت الراحة \\
\hline معنوي & & $\varepsilon, r \leqslant$ & $1 r, r q$ & $v, 1$ & 10,11 & $\Lambda, 7$ & سرعة . ب م \\
\hline معنوي & & $r, V I$ & $\varepsilon, 1 r$ & $r, \leqslant 1$ & $r, \wedge r$ & $r, r_{0}$ & الوثب الى الاعلى \\
\hline معنوي & & $\varepsilon, \cdot 0$ & $r, \wedge \varepsilon$ & $1, \mu 1$ & $\varepsilon, 01$ & $1, r \mu$ & الوثب الطويل الثبات \\
\hline معنوي & & $r, r q$ & $1 \leqslant, 0$ & $V, Y Y$ & $10,0 \leqslant$ & 9.9 & الرشاقة \\
\hline معنوي & & 7,0 & $19, Y 1$ & 11. & Yq,19 & 119 & النبض بعد الجهر \\
\hline
\end{tabular}

يبين الجدول (ه) الوسط الحسابي والانحراف المعياري وقيمة (ت) ستودنت المحتسبة جيث ظهر وجود فروق ذات دلالة معنوية عند مستوى ه.,. في جميع المتغيرات في الاختبار القبلي والاختبار البعدي ،لان قيمة (ت) المحتسبة اكبر من قيمة (ت) الجدولية والبالغة (Y,Y ( ) في كافة متغيرات البحث ولصالح الاختبار البعدي وهذا يؤكد ان البرنامج المعد للمجموعة التجريبية له تاثير ايجابي على كافة المتغيرات البدنية وعملية قياس النبض وقت الراحة ويعد الجهر مباشرة.

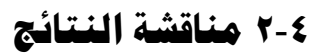

من اجل رفع مستوى الرياضي يجب ان تستعمل وسائل متعددة ومنها التمارين اللاهوائية والتمارين الهوائية التي تاتي بالدرجة الاولى لتطوير المستوى في فعالية المنافسة الممتازة ويجب ان تكون مناسبة لمتطلبات المستوى في اللعبة او الفعالية ومتطلبات بناء المستوى الطويلة الاجل ويعمل على رفع قابلية تقبل حمل التدريب تدريجيا 


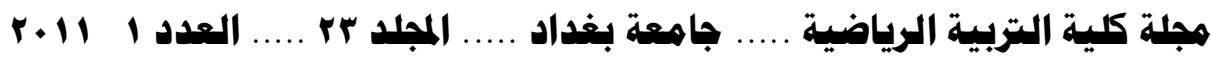

وتطور وتثبت المستوى الرياضي وتسرع في عمليات اعادة الثفاء، وان قابلية التحمل وسرعة العودة الوضع الطبيعي لها علاقة بقابلية القلب والدورة الدموية.

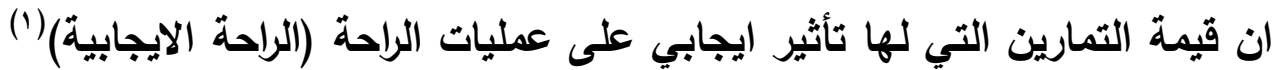

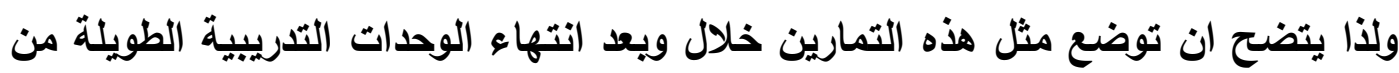
اجل ازالة ظواهر التعب بسرعة.

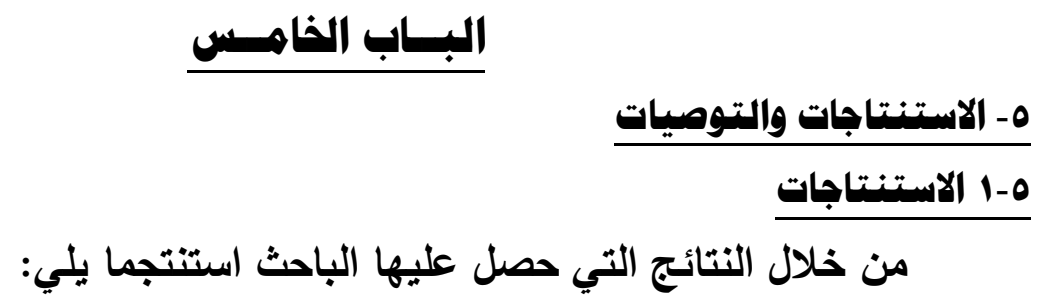

1. هناك فروق ذات دلالة غير معنوية في كافة الاختبارات القبلية للمجموعة الضابطة والمجموعة التجريبية في كافة المتغيرات. r. هناك فروق ذات دلالة معنوية في الاختبار البعدي للمجموعة الضابطة وإلمجموعة التجريبية في كافة المتغيرات. r. هناك فروق دالة معنوية في الاختبار القبلي والبعدي للمجموعة التجريبية في كافة

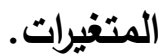
ــ البرنامج المطبق على المجموعة التجريبية له تاثير ايجابي على افراد العينة. ه. ظهور بعض الفروقات بي الاوساط الحسابة لصالح المجموعة التجريبية.

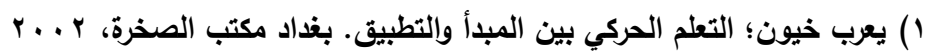




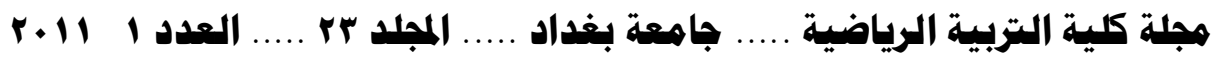

$\underline{\text { r-o }}$

يوصي الباحث بما يلي:

ا ـ يوصي الباحث بضرورة ادخال التمارين التلاهوائية ضمن برنـامج الوحدات التدريبية

وخاصة لأ فرق الارجة الاولى والممتازة.

r · يوصي الباحث بضرورة اجراء اختبارات دورية على فرق المنتخبات لمعرفة التطور الحاصل من التمارين اللاهوائية.

r. اجراء اختبارات دورية على فرق بغداد ومقارنتها مع فرق المحافظات.

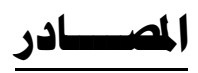

ه ابو العلا احمد ومحمد حسن علاوي؛ فسيولوجيا التدريب الرياضي.طا القاهر، دار الفكر العربي.

ه ابو العلا احمد؛ بيولوحيا الرياضية. القاهرة ،دار الفكر العربي،هو 99 ا. > ابو العلا احمد؛ بيولوحيا الرياضية. القاهرة دار الفكر العربي، هو 99 ه ريسان خريبط؛ القياسات والاختبارات في التربية البلنية والرياضية.جامعة البصرة \& كمال عبد الحمبا ومحمد صبحي حسنين؛ اللياقة البذنبة ومكونـات الاسس النظريـة الاعداد البدني طرق القياس.طء : القاهرة، دار الفكر العربي، I . . . .

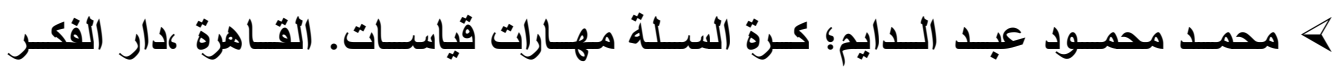
العربي، ؛ 999

> موسى فهمي ابراهيم؛ اللياقة البلنية والتـديب الرياضـي - الاعداد اللني.القاهرة ،

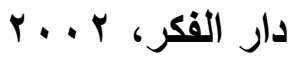
\& وجيه محجوب واحمد بلري؛ نظريات التعلم والتطور الحركي. عمان 


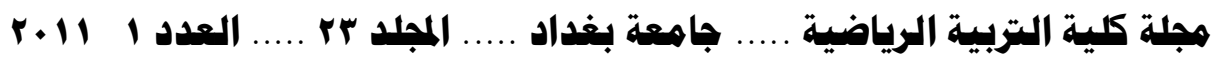

وديـع ياسسين وحسـن العبيـدي؛التطبيقات الاحصسائية واسـتخدامات الحاسـوب في

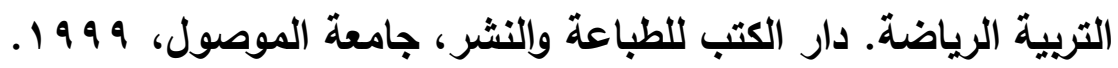

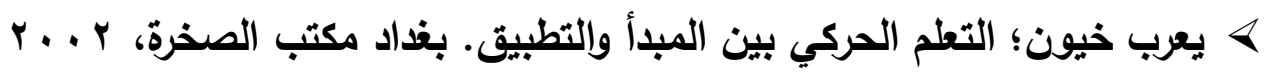

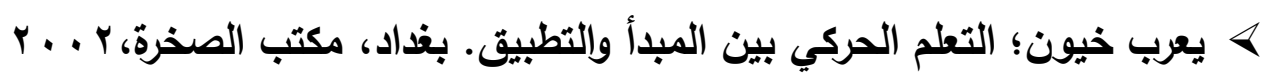

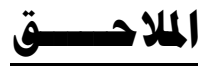 \\ البرنامه التدريبي للعينة التبريبية}

الوحدة التدريبية الاولى

\begin{tabular}{|c|c|c|}
\hline الزمن & المحتوى المنفذ & اجزاء البرنامج \\
\hline 10 & 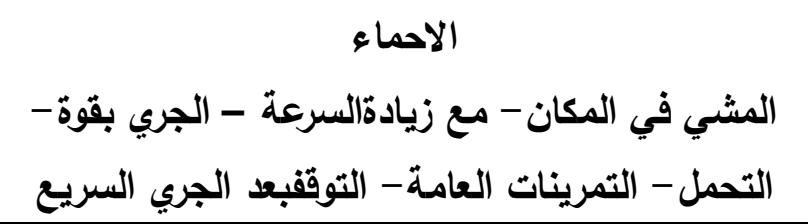 & الجزء التحضيري \\
\hline • • & 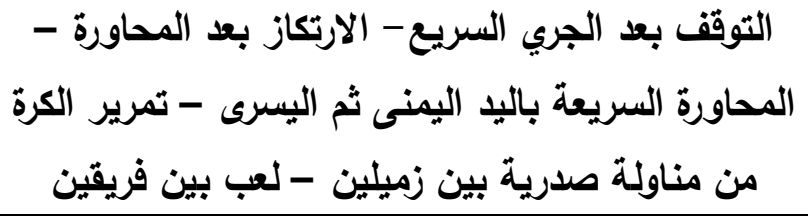 & الجزء الرئيسي \\
\hline دo & تمارين تهدئة باشكال مختلفة & الجزء الختامي \\
\hline
\end{tabular}




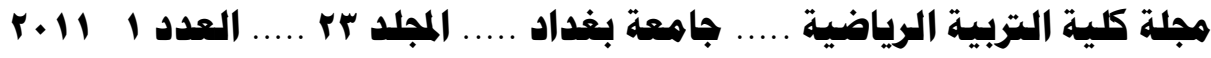

الوحدة التدريبية الثانية

\begin{tabular}{|c|c|c|}
\hline الزمن & المحتوى المنفذ & اجزاء البرنامج \\
\hline 10 & 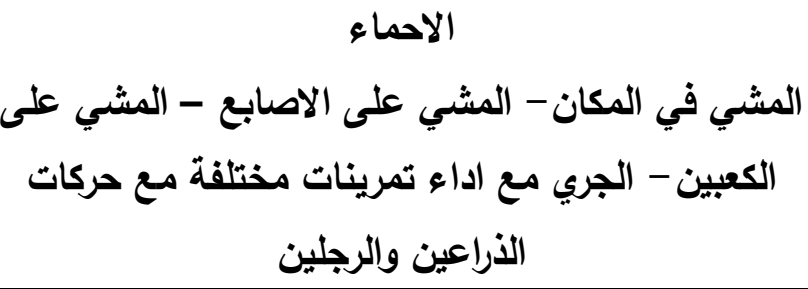 & الجزء التحضيري \\
\hline •r. זעد & 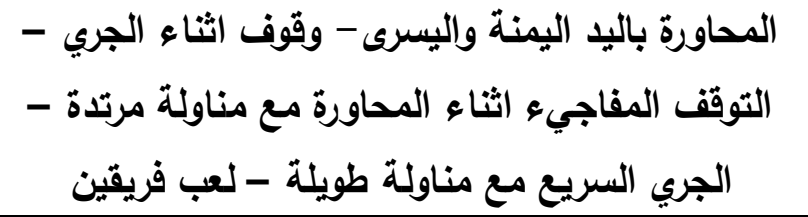 & الجزء الرئيسي \\
\hline هد & لعبة صغيرة لتهدة الجسم & الجزء الختامي \\
\hline
\end{tabular}

الوحدة التدريبية الثالثة

\begin{tabular}{|c|c|c|}
\hline الزمن & المحتوى المنفذ & اجزاء البرنامج \\
\hline 10 & 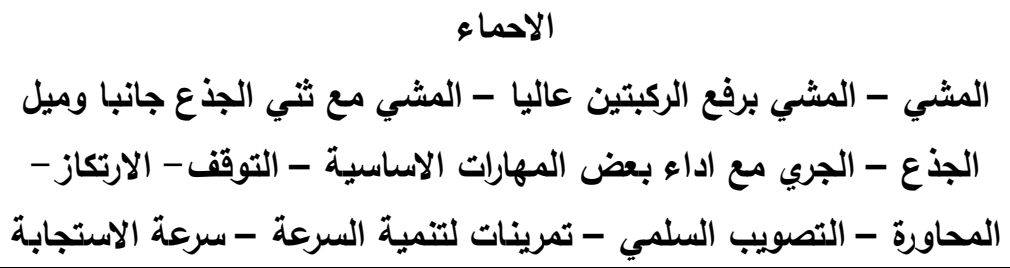 & الجزء التحضيري \\
\hline • זי זמد & 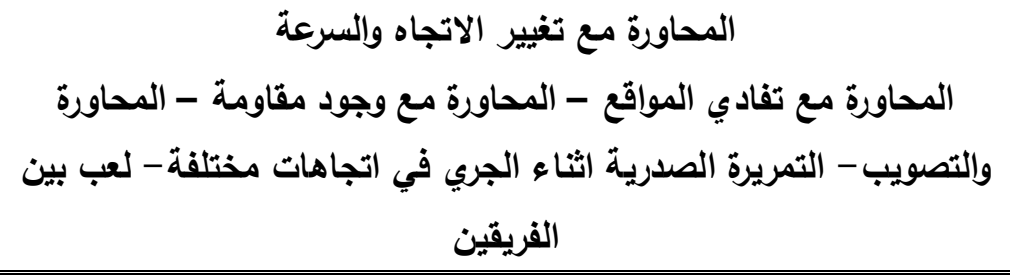 & الجزء الرئيسي \\
\hline دo & لعبة صغيرة & الجزء الختامي \\
\hline
\end{tabular}

